\title{
A política pública de ação afirmativa da educação superior indígena na Universidade Federal do Paraná (UFPR) sob o olhar de uma secretária executiva
}

\author{
The public policy of affirmative action of indigenous higher education in the Federal \\ University of Paraná - UFPR under the view of an executive secretary
}

\author{
Valéria dos Santos de Oliveira ${ }^{1(D)}$, Rodrigo Rossi Horochovski ${ }^{2}$ (D) \\ ${ }^{1}$ Universidade Federal do Paraná (U), Brasil, Doutoranda em Meio Ambiente e Sustentabilidade (UNEMAT), e-mail: \\ valeriaso238@gmail.com \\ ${ }^{2}$ Universidade Federal do Paraná (UFPR), Brasil, Doutor em Sociologia Política (UFSC), Professor associado no curso de \\ Administração Pública e nos Programas de Pós-Graduação em Ciência Política e Desenvolvimento Territorial Sustentável \\ (UFPR), e-mail: rodrigoh33@gmail.com
}

\section{RESUMO}

A Universidade Federal do Paraná (UFPR) se mostrou uma das pioneiras na implementação da política de educação superior indígena, pois em 2004 já realizava discussões nesta temática, o que culminou na Resolução n. 37/2004 do Conselho Universitário (COUN). Considerando tal afirmativa, este artigo tem como objetivo analisar a política pública de ação afirmativa pelo viés da educação superior indígena na UFPR, considerando a atuação e experiência de uma Secretária Executiva nessa área e temática. Para tanto, realizou-se uma aproximação teórica entre os conceitos inerentes ao secretariado executivo, políticas públicas, ações afirmativas; política educacional superior indígena - específica de ingresso na instituição de ensino investigada. Na metodologia contemplou-se o Modelo de Múltiplos Fluxos, o Estudo de Caso e a abordagem da análise de conteúdo. O destaque foi dado à formação da agenda política, cotejando entrevistas com os gestores e informantes-chave da implementação da política na UFPR. Por fim, como resultado localizou-se a agenda nessa conjunção política considerando os elementos históricos e institucionais, a ocorrência da ação do governo no papel dos gestores da universidade, ainda a dos movimentos sociais, da comunidade acadêmica e verificou-se a mudança das ações políticas principalmente na gestão 2002/2006.

Palavras-chave: Políticas Públicas. Educação Superior Indígena. Secretária Executiva.

\begin{abstract}
The Federal University of Paraná (UFPR), proved to be a pioneer in the implementation of indigenous higher education policy, since in 2004, it already had discussions on this theme, that brought as a result the resolution number 37/04 of the University Council (COUN). Considering this statement, this paper aims to analyze the public policy of affirmative action by the bias of indigenous higher education at UFPR, considering the performance and experience of an Executive Secretariat in this area and thematic. Therefore, a theoretical approach was carried out between the concepts inherent to the executive secretariat, public policy, affirmative actions, indigenous higher education policy - the specifically of admission the educational investigated. In the methodology, we contemplated the Multiple Streams Models, Case Study and the Content Analysis approach. The emphasis was given to the agenda formation, collating interviews with managers and key informants of the implementation of the policy in UFPR. Nevertheless, as result, located the agenda in this political conjunction considering the historical and institutional elements, the occurrence of government action in the role of institutional managers, as well as the social movements, the academic community and there was a change in political actions mainly in the 2002/2006 management.
\end{abstract}

Keywords: Public Policies. Indigenous Higher Education. Executive Secretariat. 


\section{INTRODUÇÃO}

O perfil atual do profissional de Secretariado Executivo merece destaque por sua multifuncionalidade, também conhecida por polivalência, em nichos como o de assessor, consultor, empreendedor, cogestor e até mesmo gestor em determinados casos.

Para além de toda a gama de atuação dentro das técnicas secretariais, seu papel se fortaleceu expandindo para novas áreas como a de mentoria, consultoria, projetos, empreendedorismo e com novos e/ou renovados olhares para outras dimensões: das habilidades pessoais, ambientais, da assessoria humanizada, do intraempreendorismo, do marketing pessoal, da comunicação, das relações de gênero e diversidade, da interdisciplinaridade, da interculturalidade, entre outras, já destacadas por autores como Nonato (2009), Sabino e Marchelli (2009), Medeiros e Hernandes (2010), Brito (2015), Giorni (2017), Souza, Viana e Silva (2017), Brito e Sampaio (2018) e Santiago e França (2018).

Não obstante este aperfeiçoamento nos remete às origens da profissão com a figura tão emblemática dos escribas, que como proposto por Nonato $(2009$, p. 81) “era personagem da antiguidade que dominava amplos conteúdos intelectuais, o que significava um grande privilégio para a época", e não diferente do que o profissional de secretariado executivo vivencia nessa Era, considerando, ainda, as dimensões globais, econômicas, ambientais, políticas e sociais, nas quais estes trabalhadores estão inseridos.

Partindo-se deste aperfeiçoamento em diversos segmentos e temas contemporâneos compreende-se a atuação de um profissional de Secretariado Executivo que desempenha suas funções em órgão público, com as políticas públicas e no seu desdobramento com as políticas afirmativas.

Portanto, é necessário compreender as perspectivas de políticas públicas, políticas sociais e políticas afirmativas. Alguns autores mencionam que a política pública é a ação ou não ação do governo (SOUZA, 2012; SILVA, 2012; OLIVEIRA, 2013). Na visão de Kingdon (2011), as políticas públicas podem ser percebidas como um conjunto formado por processos que compreendem o estabelecimento de uma agenda, a especificação das alternativas e a escolha, a escolha final entre as alternativas específicas, e a implementação da decisão.

A ênfase na política social, principalmente na política afirmativa ou de ação afirmativa, é a que dá o direcionamento ao desenvolvimento desta pesquisa. A Constituição Federal de 
1988, marcou aspectos importantes no que se refere à mudança de visão sobre a educação, especialmente, das questões ligadas à diversidade, cultura, movimentos sociais, entre outras. No Brasil, a ação afirmativa é ainda desconhecida por grande parte da população. Entre aqueles mais familiarizados, a discussão se desenvolve principalmente em termos de 'políticas de cotas' (MOEHLECKE, 2000, p.4). Embora essa afirmação seja de um tempo atrás ela infelizmente ainda é recorrente e destaca-se que Política de Cotas é um tipo entre outros de ação afirmativa.

Dessa forma, o estudo objetiva analisar a política pública de ação afirmativa pelo viés da educação superior indígena. Por conseguinte, a investigação trata de um estudo de caso na Universidade Federal do Paraná (UFPR), considerando a atuação e experiência vivenciada por uma Secretária Executiva nessa área e temática intercultural, questionando: Quais elementos institucionais e históricos levaram à adoção dessa política na UFPR? A referida instituição foi uma das primeiras universidades federais a implantar vagas suplementares para os estudantes indígenas através do IV Vestibular dos Povos Indígenas, no ano de 2004, com o ingresso dos estudantes na instituição, em 2005.

No processo metodológico deste trabalho, o enfoque foi descrito através da análise da política no Modelo de Múltiplos Fluxos, proposto por Kingdon (2011), que trata de percorrer os fluxos do processo decisório, desencadeando em uma janela de oportunidades. Com isso, foi possível integrar uma agenda política (agenda setting), que compreende as fases do ciclo de políticas públicas, que são muito importantes nesse processo. Para tal análise, a abordagem se deu aos elementos que constituem a fase pré-decisória da política pública, através do Estudo de Caso (YIN,2001) na Instituição de Ensino Superior (IES) estudada.

No que concerne às análises dos resultados deste estudo, propõe-se a técnica da análise de conteúdo, conforme sugere Bardin (1979), obtido através de entrevistas com roteiro semiestruturado destinadas aos atores dessa conjunção institucional. Essas entrevistas com os gestores e informantes-chave que estiveram presentes na implementação da política na referida instituição foram pensadas e elencadas por uma rede de relacionamentos advindos da experiência dos pesquisadores e por indicação de outros informantes pelos entrevistados, dessa forma, tornou-se necessária uma delimitação dos envolvidos.

O artigo contempla o referencial teórico, abordando as políticas públicas compreendendo o que são e o seu contexto dentro da temática proposta, as políticas e ações afirmativas e o profissional de secretariado executivo e sua atuação em múltiplas dimensões. 
Em seguida apresenta-se os procedimentos metodológicos, parte-se para a apresentação e análise dos resultados e por fim, as considerações finais, buscando responder à pergunta da pesquisa, com alguns apontamos em relação aos seus desdobramentos, propondo novos questionamentos que podem ser estudados em pesquisas futuras que dialoguem nesse bojo.

\section{AS POLÍTICAS PÚBLICAS}

A política pública como área de conhecimento e disciplina acadêmica nasce nos Estados Unidos. Lá observa-se que a ênfase se dá nos estudos "sobre a ação do governo"; entretanto na Europa a área de políticas públicas surge como desdobramento de trabalhos baseados em teorias explicativas sobre o papel do Estado e do Governo, produtor de políticas públicas.

É evidente que não há consenso sobre a definição de políticas públicas, entretanto para explicitar o que são políticas públicas, Souza (2012) nos apresenta a definição de diversos autores, destaca-se: Mead (1995) que a define como "um campo dentro do estudo da política que analisa o governo à luz de grandes questões públicas" e Lynn (1980) como "um conjunto de ações do governo que irão produzir efeitos específicos" (SOUZA, 2012, p. 68). Para tanto observa-se que os estudos sobre políticas públicas, ou sobre "o governo em ação", não são novos na ciência política, se destacaram após a emergência de programas de bem-estar social (OLIVEIRA, 2013).

Percebe-se que há uma conjunção de atores que podem estar envolvidos de alguma maneira no processo de políticas públicas, agindo direta ou indiretamente em aspectos ou fases delas. Assim, Silva (2012, p. 21) destaca "a política pública envolve vários atores e níveis de decisão, embora seja materializada nos governos, e não necessariamente se restringe às participações formais, já que os informais são também importantes”. Dessa forma, sublinha-se a participação dos movimentos sociais, das comunidades acadêmicas, comunidade externas e diversos atores envolvidos no processo político da agenda de pesquisa.

Dentro das políticas públicas existe um ciclo, denominado "Ciclo das políticas públicas" ou "fases da política", ou ainda, fases do "processo de políticas públicas", que pode ser constituído por definição de agenda, identificação de alternativas, avaliação das opções, seleção das opções, implementação e avaliação. A ênfase nessa pesquisa foi dada na definição/formação ou construção da agenda.

Revista Expectativa, Toledo/PR, v.20, n. 4, p. 133-154, out./dez., 2021. 
Figura 1 - Ciclo das Políticas Públicas

\begin{tabular}{|c|c|c|c|c|c|c|}
\hline $\begin{array}{l}\text { Identificação } \\
\text { do Problema }\end{array}$ & $\begin{array}{l}\text { Formação da } \\
\text { Agenda }\end{array}$ & $\begin{array}{l}\text { Formulação } \\
\text { de } \\
\text { Alternativas }\end{array}$ & $\begin{array}{l}\text { Tomada } \\
\text { de } \\
\text { Decisão }\end{array}$ & $\begin{array}{l}\text { Implemen- } \\
\text { tação }\end{array}$ & Avaliação & Extinção \\
\hline
\end{tabular}

Fonte: Adaptado de Secchi (2014).

O Modelo utilizado é o Modelo de Múltiplos Fluxos apresentado por Kingdon (2011) demonstra que os fluxos quando se encontram ou se interconectam (coupling) geram a janela de oportunidade e, possivelmente, a formulação/mudança na agenda. Os fluxos são: 1) o fluxo de problemas (problem stream); 2) o fluxo de soluções ou alternativas (policy stream); e 3) o fluxo de política (political stream) (KINGDON, 2011).

Figura 2 - Modelo de Múltiplos Fluxos

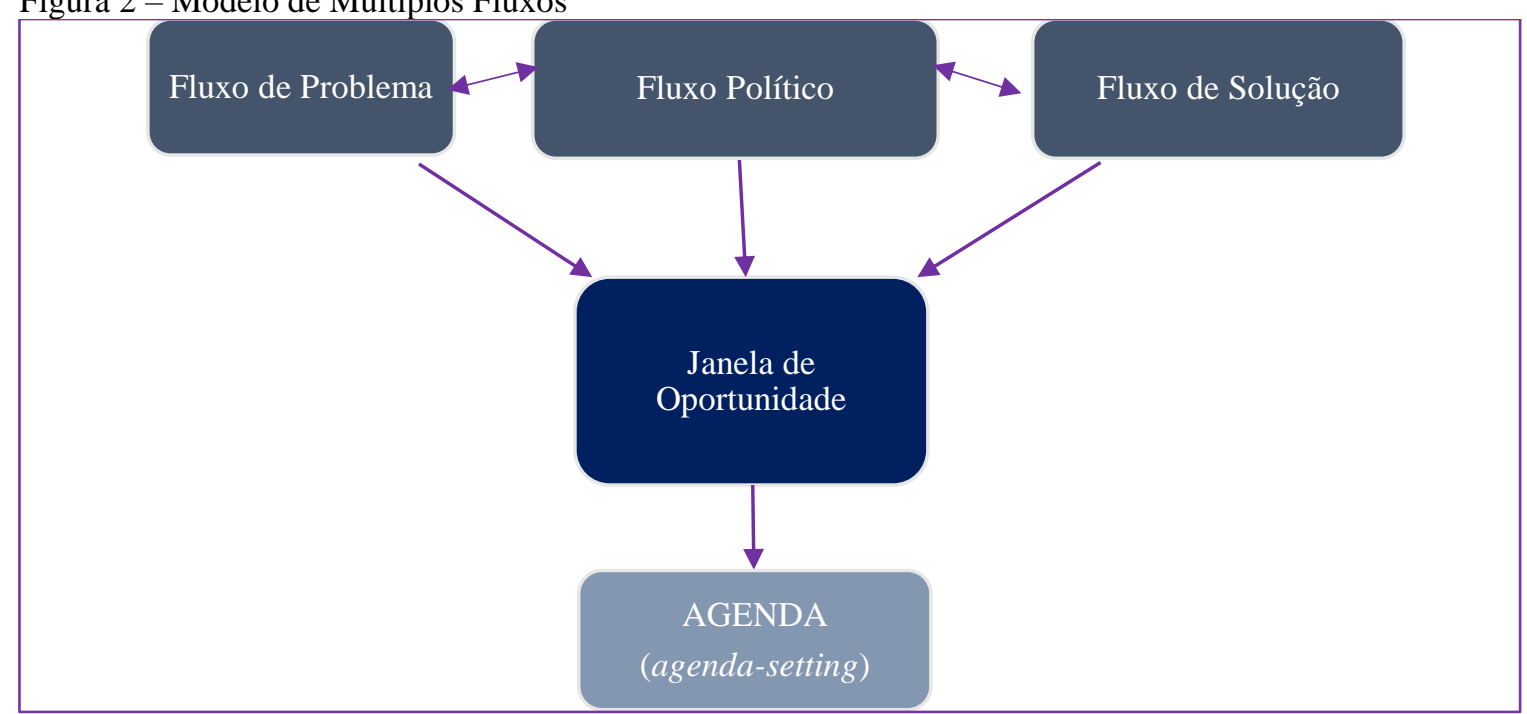

Fonte: Oliveira (2016) com base em Kingdon (2011) e adaptada de Capela (2004).

No que se referem às categorias de análise, estas foram tratadas de duas formas: as categorias gerais que são os Múltiplos Fluxos de Kingdon (2011), e as categorias específicas os elementos históricos (eventos e feedback das ações governamentais), as dificuldades (crises e símbolos); os elementos institucionais (clima ou humor) e o impacto, importância e decisão advindo do Modelo de Múltiplos Fluxos que se referem aos elementos destacados e que compõem as perguntas realizadas.

Revista Expectativa, Toledo/PR, v.20, n. 4, p. 133-154, out./dez., 2021. 


\subsection{POLÍTICAS E AÇÕES AFIRMATIVAS}

Ações afirmativas, políticas afirmativas, políticas de ação afirmativas são diferentes terminologias para tratar dessa dimensão, que diz respeito a inclusão e, consequentemente, ao debate da exclusão de pessoas em diferentes espaços. É a necessidade de se voltar o olhar de forma mais apurada à questão das ditas “minorias”, conforme Munanga (2007) que propõe uma pertinente explicação sobre as ditas minorias, grupos e/ou pessoas com prejuízos históricos, como os negros(as), indígenas, pessoas com deficiência, pessoas socialmente vulneráveis, entre outras.

Assim, ações afirmativas "são políticas públicas destinadas a atender grupos sociais que se encontram em condições de desvantagem ou vulnerabilidade social em decorrência de fatores históricos, culturais e econômicos" (Fonseca, 2009, p. 110). A necessidade dessas correções de distorções históricas e sociais encontram-se presentes no escopo dessa pesquisa.

Pode-se também destacar que as ações afirmativas são políticas públicas feitas pelo governo ou pela iniciativa privada com o objetivo de corrigir desigualdades dentre elas as raciais, presentes na sociedade, acumuladas ao longo de anos. A ação afirmativa só se faz necessária quando percebemos um histórico de injustiças e direitos que não foram assegurados conforme descrito pela Secretaria de Políticas de Promoção da Igualdade Racial (SEPPIR, 2015).

Os movimentos sociais (à exemplo: negros, indígenas, entre outros) que lutaram por várias pautas sociais e dentre elas a educação estão no bojo das políticas sociais compensatórias.

\footnotetext{
Consistem em políticas públicas (e também privadas) voltadas à concretização do princípio constitucional da igualdade material e à neutralização dos efeitos da discriminação racial, de gênero, de idade, de origem nacional e de compleição física. Impostas ou sugeridas pelo Estado, por seus entes vinculados e até mesmo por entidades puramente privadas, elas visam combater não somente as manifestações flagrantes de discriminação de fundo cultural, estrutural, enraizada na sociedade. De cunho pedagógico e não raramente impregnadas de caráter de exemplaridade, têm como meta, também, o engendramento de transformações culturais e sociais relevantes, inculcando nos atores sociais a utilidade e a necessidade de observância dos princípios do pluralismo e da diversidade nas mais diversas esferas do convívio humano (GOMES, 2001, p. 6-7).
}

Esses conceitos de ação afirmativa nos permitem compreender do que elas tratam e da importância e impacto delas na sociedade, nas agendas políticas, na perspectiva da educação e na vida desses atores sociais.

Revista Expectativa, Toledo/PR, v.20, n. 4, p. 133-154, out./dez., 2021. 
Para compreender a necessidade de uma ação afirmativa, é preciso, antes de tudo, compreender o contexto social vivido por um país, por isso o que gera preconceito por parte de setores da sociedade em muitos casos é analisar uma ação afirmativa sem antes entender o histórico que precedeu a política pública (SEPPIR, 2015).

Na IES estudada, em relação à educação superior indígena, as vagas são suplementares, porém, a Lei 12.711/12, comumente tratada como "Lei de Cotas", prevê também as cotas para ingresso de estudantes indígenas. Algumas instituições de ensino superior estaduais também utilizam as cotas ou outras políticas para o ingresso de indígena.

Segundo Grupioni (2002, p. 95), “a Constituição de 1988 assegurou o direito à diferença cultural, reconhecendo suas organizações sociais, costumes, línguas, crenças e tradições dos povos indígenas". Os indígenas sem dúvida são atores sociais que participam e querem participar através de movimentos, reinvindicações, dessa possibilidade de estar presente e contribuir com a política educacional indígena em todos os seus matizes.

Portanto neste contexto, o Profissional de Secretariado em questão, entre outros profissionais, deve compreender e aperfeiçoar suas ações direcionadas à interculturalidade, expandir seu conhecimento político, social, econômico, ambiental; interseccionando com as mais diversas culturas, independente se sua atuação seja na iniciativa privada, em órgãos públicos, em outras instituições ou qualquer frente de atuação e deve-se respeitar e procurar compreender essas alteridades, dentro de suas cosmovisões.

\subsection{O PROFISSIONAL DE SECRETARIADO EXECUTIVO E SUA ATUAÇÃO EM MÚLTIPLAS DIMENSÕES}

Atualmente, o profissional de Secretariado Executivo exerce suas atividades de forma mais empreendedora e decisória, estimulando pessoas e orientando unidades operacionais, percebendo e realizando mudanças internas e externas. A profissão está devidamente regulamentada por lei, devendo exercê-la aqueles que, além das habilidades e competências pessoais, possuírem formação acadêmica para tal.

A palavra secretário tem origem no latim secretarium, cujo significado é "lugar retirado, solidão, audiência", vem da palavra secretum - "particular", "segredo" "mistério" (NONATO JÚNIOR, 2009). O que significa estar em uma posição privilegiada e atuando com assuntos de 
extrema cautela, sigilo, relevância, importância e que geram reflexões e impactos (positivos ou negativos para as instituições).

A origem da profissão aparece em diferentes contextos históricos, por exemplo, no religioso e na antiguidade: "Religiosos atribuem à figura de Eva o papel de primeira secretária ao assessorar Adão ou vice-versa. [...] na mitologia antiga, diversos deuses e heróis assessoram outras na criação de todas as fontes de conhecimento natural, cultural e espiritual." (Nonato, 2009, p. 81).

Em outro contexto, os escribas foram considerados os primeiros secretários da história, eles constituíram uma importante classe:

\footnotetext{
Para qualificar-se como escriba, o indivíduo frequentava importantes escolas de Mênfis ou Tebas. Formar-se escriba significava ingressar na classe oficial culta, isentando-se do trabalho servil e vislumbrando a possibilidade de ocupar os elevados cargos públicos. E assim a profissão foi ganhando espaço nas organizações sociais, comerciais e políticas, assumindo diferentes nomenclaturas, mas mantendo sempre duas principais características: administração e escrita (SABINO; ROCHA, 2004, p.5).
}

A Lei $\mathrm{n}^{\circ} .6 .556 / 78$ de 5 de setembro de 1978, foi o primeiro documento que reconhecia a profissão secretarial. A Lei, entretanto, dependia de regulamentação e era ainda insuficiente para atender às aspirações do secretariado brasileiro. Ao longo dos anos as mudanças foram ocorrendo, as reivindicações por melhores condições de trabalho foram frequentes e um longo caminho percorrido. A regulamentação da profisssão, ocorreu através Lei n. 7.377, de 30 de setembro de 1985, reconhecendo-se o trabalho executado pela Associação Brasileira de Entidades de Secretárias (ABES) e a Federação Nacional das Secretárias e Secretários (FENASSEC).

Foi complementada pela Lei 9.261/96 de 10 de janeiro de 1996. O contexto atual é outro, a forma de se fazer atuação secretarial e o saber que o contorna também é distinta, forma um tanto arrojada, com diversos olhares e possibilidades e várias contribuições sociais.

A importância da profissão é indiscutível e seus avanços consideráveis, dessa maneira com inúmeras atribuições e com a competência para atuar como empreendedor, comunicador, coaching, com habilidade para trabalhar com a tecnologia e para gerenciar conflitos ou demais situações da rotina de trabalho, sua presença no local de trabalho é fundamental. Nesse aspecto, Nonato (2009, p. 41) corrobora na perspectiva intelectual e de gestão do conhecimento: "o secretário vem alargando conceitos e práticas intelectuais ligados ao seu trabalho, superando 
concepções presas aos recursos operacionais, direcionando-se para a gestão do conhecimento humano que perpassa as práticas executivas [...]".

Reforça-se, todavia, que o profissional de Secretariado Executivo na atualidade é reconhecido por sua gama de atuações e seu perfil intelectual, para além das habilidades técnicas e operacionais. Seu papel se fortaleceu expandindo para novas áreas e apurando novos e diferenciados olhares em outras dimensões, já mencionadas na introdução deste estudo.

Contribuindo neste contexto, o profissional de secretariado tem perfil arrojado e sua formação em múltiplas áreas, desde administração a consultoria, adentrando na área cultural, oferece a oportunidade de atuação como um conselheiro, como descreve Brito (2015).

Neste bojo, Giorni (2017, p. 70) ressalta que: “o perfil do profissional de Secretariado mudou muito, e a tendência é de se alterar ainda mais, uma vez que é uma profissão que acompanha todas as transformações ocorridas no mercado de trabalho". Isso demonstra multiplicidade, realizando diversas atividades, vivenciando e superando desafios e indo ao encontro de novos conhecimentos, com dimensão multifacetada, encarando o trabalho, as vivências e as oportunidades por diferentes ângulos e olhares.

Ao tocar na questão da interdisciplinaridade, compreendendo-a como a integração das disciplinas trabalhadas, com uma abrangência do campo de visão nas diversas disciplinas da área secretarial, percebe-se a dimensão e alcance de diferentes assuntos e possibilidades de compreensão, reflexão e atuação.

A compreensão da interculturalidade como interação ou inter-relacionamento cultural, estar "entre culturas", "no meio de culturas". Relacionando-se com a área secretarial, Brito (2015, p. 47) propõe “que o profissional de secretariado executivo busque o máximo de aprendizado, conhecimento e sensibilidade humana quanto lhe for necessário, principalmente no que diz respeito ao convívio social e à percepção do outro".

Tanto a interdisciplinaridade, quanto a interculturalidade perpassam com significativa contribuição a discussão presente na pesquisa, pela construção e visão de diferentes áreas do saber e a atuação multiprofissional da equipe de trabalho que atende aos estudantes pertencentes às políticas afirmativas na referida Universidade, nessa pesquisa com destaque ao viés da atuação da profissional de secretariado.

\footnotetext{
${ }^{1}$ Ver Laraia (2000) sobre Cultura.
}

Revista Expectativa, Toledo/PR, v.20, n. 4, p. 133-154, out./dez., 2021. 
As universidades e o mercado de trabalho recebem atualmente estudantes e profissionais de diversas raças, etnias, espaços sociais; como indígenas, quilombolas, pessoas do campo, entre outros, pessoas advindas de diferentes vivências e saberes locais, pessoas que fizeram ou fazem parte de políticas afirmativas (negros, pessoas com deficiência, oriundos de escola pública, com vulnerabilidade social), a área secretarial comporta uma visão global do ser humano, das suas habilidades e de suas fragilidades, da compreensão e empatia com pessoas de diferentes contextos e locais.

Perante tantas evoluções, a escolha desse tema dentro da área secretarial é de extrema relevância, pois descortina a possibilidade de atuação para além da aplicação do trabalho técnico desempenhado seja em órgãos públicos e/ou privados ou em diferentes contextos (empreendedorismo, terceiro setor, consultoria, etc) mas na perspectiva da ampliação de da atuação secretarial. Isso tudo dialoga diretamente com a perspectiva da assessoria aberta ${ }^{2}$ (Nonato, 2009, p. 160) que "envolve todas as práticas secretariais que extrapolam o mero ambiente das organizações, e que, necessitam estabelecer as relações entre assessorias e outras áreas do conhecimento".

Urge expandir a reflexão e atuação para as questões sociais, políticas, ambientais, econômicas, humanas e isso permitirá um saber (como/saber) prático relevante. Portanto, a experiência pessoal da profissional de Secretariado Executivo no órgão público na temática intercultural busca traduzir um pouco dessa possibilidade de expansão e de fomentar mais adeptos a essa visão e prática.

\section{PROCEDIMENTOS METODOLÓGICOS}

Trata-se de um estudo de caso para se compreender a conjunção, o histórico e a implementação da política educacional superior indígena na UFPR com a participação dos atores (gestores e informantes-chave) envolvidos nesta política, através de entrevistas individuais, com roteiro de entrevista semiestruturado.

Para uma aproximação da problemática que orienta o presente estudo, a opção foi por utilizar a pesquisa aplicada, com abordagem qualitativa perpassando no momento da análise dos resultados pela abordagem quantitativa relativa ao tratamento de dados expostos nas

\footnotetext{
${ }^{2}$ A respeito de da assessoria aberta verificar Nonato (2009) sobre Assessorab (Eixo 4).
}

Revista Expectativa, Toledo/PR, v.20, n. 4, p. 133-154, out./dez., 2021. 
entrevistas. Para compreensão da perspectiva da análise da política, foi utilizado o embasamento teórico do Modelo de Múltiplos Fluxos (Multiple Streams Model) (KINGDON, 2011).

Foram realizadas análise dos documentos, levantamento de pressupostos teóricos; definição das categorias; análise qualitativa e quantitativa das entrevistas; conjunção dos Múltiplos Fluxos, abertura da Janela de Oportunidades e formação da Agenda. Aplicou-se entrevistas com a participação de cinco gestores e/ou informantes-chave que estiveram presentes na implementação da política na Universidade Federal do Paraná - UFPR, aqui intitulados como entrevistados a, b, c, d, e, resguardando, assim, o anonimato dessas pessoas. Atores estes com atuação como pró-reitores, docentes, técnicos administrativos, entre outros sendo que alguns fizeram parte da Comissão do Plano de Metas de Inclusão Racial e Social na UFPR (UFPR, 2004a).

Ressalta-se a necessidade do estudo de caso, subsidiado por Yin (2001), pois os estudos de caso representam a estratégia preferida quando se colocam questões do tipo "como" e "por que", quando o pesquisador tem pouco controle sobre os eventos e quando o foco se encontra em fenômenos contemporâneos inseridos em algum contexto da vida real (YIN, 2001). Com vistas a dialogar com as variáveis presentes nos discursos dos gestores e informanteschave, destacamos o Modelo de Múltiplos Fluxos (Multiple Streams Model) que foram elencados como categorias gerais, cunhado por Kingdon (2011).

No processo de formulação de políticas públicas encontra-se o processo de formação da agenda de políticas governamentais (agenda-setting), que aparece a partir de um problema, questionando como uma questão se torna importante e/ou o que chama a atenção do governo/empreendedores políticos (policy entrepreneurs) para, assim, passar a integrar a agenda (KINGDON, 2011).

Por fim, para a análise dos resultados obtidos através das transcrições das entrevistas, utilizou-se o recurso da análise de conteúdo, subsidiado pela técnica proposta por Bardin (1979). A estruturação da análise de conteúdo, no que se refere ao método, se apresenta da seguinte forma: organização da análise por fases - 1) A pré-análise; 2) A exploração do material; e 3) $\mathrm{O}$ tratamento dos resultados, a inferência e a interpretação, que foram seguidas passo a passo.

Revista Expectativa, Toledo/PR, v.20, n. 4, p. 133-154, out./dez., 2021. 
O conteúdo trazido na fala de cada gestor e/ou informante-chave possibilitou compreender sob suas perspectivas os elementos históricos, institucionais, enfim, os encaminhamentos realizados para a efetivação de uma agenda de discussão e ação da política afirmativa na universidade.

No que se referem às categorias, estas foram tratadas de duas formas: as categorias gerais que são os Múltiplos Fluxos de Kingdon (2011), e as categorias específicas os elementos históricos (eventos e feedback das ações governamentais) e as dificuldades (crises e símbolos); os elementos institucionais (clima ou humor) e o impacto, importância e decisão advindo do Modelo de Múltiplos Fluxos que se referem aos elementos destacados e que compõem as perguntas.

\section{APRESENTAÇÃO E ANÁLISE DOS RESULTADOS}

Apresenta-se uma condensada parte da análise dos resultados, por considerar extensa toda a sua abrangência de aspectos. O fluxo de problema, na perspectiva da educação indígena, foi desenhado a partir dos elementos históricos (eventos e feedback das ações governamentais) e das dificuldades (crises e símbolos) para uma análise qualitativa e das frequências e ocorrências de palavras para uma análise quantitativa. Essa confirmação se estabelece através dos dados e questões presentes nas entrevistas, que aparecem tanto no âmbito nacional quanto no local. Destaca-se também o levantamento documental realizado para essa construção.

As entrevistas foram direcionadas aos gestores e informantes-chave (policy enterpreneur/empreendedores de política).

Uma das questões definidas que auxiliaram na composição deste fluxo no âmbito nacional foi: 1) Em que momento histórico a política pública educacional superior indígena foi discutida nas universidades federais?

Para tanto ao longo da pesquisa foram elaborados quadros que sistematizavam as questões. A exemplo o quadro a seguir: 
A política pública de ação afirmativa da educação superior indígena na Universidade Federal do Paraná (UFPR) sob o olhar de uma secretária executiva

Quadro 1 - Categorias e levantamentos: fluxo de problemas - âmbito nacional

\begin{tabular}{|c|c|}
\hline $\begin{array}{l}\text { CATEGORIA GERAL } \\
\text { Fluxo de Kingdon (2011): } \\
\text { Problemas (problems stream) }\end{array}$ & $\begin{array}{l}\text { Fluxo em que uma questão passa a ser um problema quando este chama } \\
\text { a atenção dos formuladores de políticas públicas, através de } 3 \\
\text { mecanismo: indicadores; eventos, crises e símbolos; e feedback das } \\
\text { ações. }\end{array}$ \\
\hline $\begin{array}{c}\text { CATEGORIA ESPECÍFICA } \\
\text { NACIONAL } \\
\text { - Elementos históricos (eventos e } \\
\text { feedback das ações } \\
\text { governamentais) } \\
\text { - Dificuldades } \\
\text { (crises e símbolos) } \\
\text { Entrevistas - Itens a serem } \\
\text { considerados qualitativamente }\end{array}$ & $\begin{array}{l}\text { RESPOSTAS DOS ENTREVISTADOS } \\
\text { - Na Constituinte, na Constituição, na Lei de Diretrizes e Bases da } \\
\text { Educação (LDB); - Ação que tramitou no Supremo Tribunal Federal } \\
\text { - Arguição de Descumprimento de Preceito Fundamental (ADPF) 186; - } \\
\text { Cotas raciais; - 2a Conferência Mundial contra o Racismo, Discriminação } \\
\text { Racial, Xenofobia e Intolerância - Conexa de Durban; - Nas pioneiras } \\
\text { Universidade do Estado do Rio de Janeiro (UERJ) e Universidade de } \\
\text { Brasília (UnB). }\end{array}$ \\
\hline $\begin{array}{l}\text { CATEGORIA ESPECÍFICA } \\
\text { Entrevistas - Itens a serem } \\
\text { considerados quantitativamente }\end{array}$ & $\begin{array}{l}\text { FREQUÊNCIA/OCORRÊNCIA DE PALAVRAS } \\
\text { (número de vezes que foram repetidas no conjunto de cada questão por } \\
\text { todos os entrevistados) } \\
\text { - Indígena(s) (31), cotas }(\mathbf{1 2}) \text {, raciais (6), ação(es) (13), constituição (9), } \\
\text { constituinte (5), universidade(s) (15) }\end{array}$ \\
\hline LEVANTAMENTOS & $\begin{array}{l}\text { Revisão bibliográfica } \\
\text { Levantamento documental } \\
\text { Questões presentes nas entrevistas por pergunta } \\
\text { Conferência de hipóteses } \\
\text { Conferência dos objetivos propostos }\end{array}$ \\
\hline
\end{tabular}

Fonte: Oliveira (2016).

Com base no Quadro 1, é possível afirmar que a análise qualitativa referente ao fluxo de problema concernente aos elementos históricos da política pública educacional superior indígena, evidencia diferentes perspectivas e pontos elencados como os de partida para a discussão da política afirmativa nas universidades federais do país, apresentando alguns eventos, leis e universidades pioneiras na discussão.

Contudo, o levantamento documental também corroborou com as repostas dos entrevistados e possibilitou averiguar que os movimentos sociais, movimentos indígenas e indigenistas reivindicaram a discussão da educação indígena nesses processos. Foram dessa maneira protagonistas, contribuíram para a entrada desses estudantes no ensino superior público, apoiados por movimentos sociais em especial pelo movimento negro. Oriundos de lutas pela garantia de políticas e de ações afirmativas, fortemente marcadas nas discussões das desigualdades nas universidades públicas federais.

Alguns documentos que trazem esses aspectos são: a Constituição Federal de 1988; a Arguição de Descumprimento de Preceito Fundamental ADPF - 186/DF; o Relatório Conferência Mundial contra o Racismo, Discriminação Racial, Xenofobia e Intolerância 
A política pública de ação afirmativa da educação superior indígena na Universidade Federal do Paraná (UFPR) sob o olhar de uma secretária executiva

Conexa Conferência Europeia contra o Racismo; a Lei de Diretrizes e Bases da Educação Nacional (LDB) - Lei 9.394 (1996) e o Relatório do Plano de Metas de Inclusão - UFPR.

Esse mesmo quadro foi replicado para outras questões que apareceram ao longo da pesquisa. Apresenta-se aqui em outro formato as respostas dos entrevistados e/ou informantes chaves: 2) Como surgiram as discussões dessa política na UFPR? Quais as dificuldades foram enfrentadas?

Os entrevistados destacaram:

O processo de ocupação do pátio da reitoria [...] A aprovação em 2004, da Resolução n. 37/04, que está sendo agora em 2015, salvo engano revogada em um todo, a resolução vai trazer essa dupla via ela vai incorporar tanto essa dimensão do debate do movimento negro e ela incorpora a partir da resolução da UnB, então não sei se tem muita diferença da resolução do CEPE da UnB a dimensão indígena. $\mathrm{E}$ depois implementação da UnB, da UERJ e não podemos esquecer também o caso do Paraná, o Paraná também é precursor nesse processo, ele é precursor porque em 2001 começa o Vestibular dos Povos Indígenas. (Entrevistado B).

[...] então ela vem da população em geral, as universidades participam como participaram para a constituinte, se não a instituição universidade, mas os movimentos sociais universitários, o movimento estudantil, movimentos dos professores, movimento dos servidores técnicos administrativos e tal e as universidades como instituição sendo arrastadas por esses movimentos mais progressistas. (Entrevistado D).

A questão da UFPR ela concretamente entra pós LDB e toda a evolução dessa área que a LDB deveria ter provocado dentro das universidades, na Federal com a eleição em 2001 tomando posse em 2002 de uma gestão que se chamou plural, dinâmica e participativa pela oposição, essa gestão tinha como força principal fazer a universidade avançar [...]. (Entrevistado A).

Nesta questão da política local apareceram documentos relativos à política em âmbito nacional, como a Constituição Federal (1988), a LDB (1996) e o Relatório da Conferência de Durban (Conferência Mundial contra o Racismo, Discriminação Racial, Xenofobia e Intolerância conexa - Conferência Europeia contra o Racismo) e ainda o Termo de Convênio com as universidades estaduais do Paraná, bem como o acordo com a Fundação Nacional do Índio (FUNAI).

O fluxo político. As questões definidas que auxiliaram na composição desse fluxo no âmbito local foram: 3) Na sua opinião, quais os atores (pessoas, instituições) influenciaram essa política? 4) Na sua opinião, quais as arenas (espaços de debates) influenciaram essa política?

Revista Expectativa, Toledo/PR, v.20, n. 4, p. 133-154, out./dez., 2021. 
$\mathrm{Na}$ análise qualitativa referente ao fluxo político concernente aos atores (pessoas, instituições) que influenciaram essa política, evidenciou-se diferentes perspectivas e pontos convergentes nos diferentes discursos para as questões da política na UFPR:

[...] mas ao incluir os estudantes indígenas na Federal, eles não foram bem recebidos porque eles não eram tratados diferentemente como era o espírito de toda a evolução desde a constituinte eles eram tratados como estudantes convencionais não teria diferença nenhuma no tratar eles, então isto gerou um problema grave, porque nós não tínhamos vagas por cursos [...] (Entrevistado A).

Sem dúvida nenhuma a comunidade indígena, a comunidade indígena eu acho que é uma das mais organizadas nesse país, na busca de seus direitos, no enfrentamento de todos os obstáculos que eles acabam tendo, e eu acho que eles são muito bravos, muito bravos e isso é uma força que não dá de tirar o protagonismo deles na questão das cotas e acho que a gente, aqui no Paraná especificamente a gente já tinha, quer dizer eles já tinham feito essa luta, essa conquista. [...] a FUNAI por obrigação institucional. As universidades em parceria com a FUNAI, porque ali sabia que ela tinha, a tá daí o governo do estado foi bastante aberto, porque os vestibulares eram feitos juntos, tanto é que eram diferenciados. (Entrevistado C).

$\mathrm{Na}$ análise qualitativa referente ao fluxo político concernente às arenas (espaços de debates) que influenciaram essa política, evidenciou-se:

\begin{abstract}
A principal arena é um espaço aberto do conflito aonde que tem uma comunidade indígena, de uma nação indígena, das diferentes nações indígenas, tem conflito e é este conflito que a universidade tem que aprender com ele porque é aprendendo com esse conflito que nós vamos propiciar uma educação mais dentro do espírito da modalidade indígena [...] (Entrevistado A).

Acho que nenhum é tão maltratado, eu não conheço na verdade, não posso dizer que não existam, mas eu não conheço espaços e não conheço atividades que estejam de alguma forma possibilitando uma melhor convivência, atendimento da população indígena, como se fosse assim um estrangeiro que chega e se mete no teu meio. (Entrevistado C).
\end{abstract}

O fluxo de soluções ou alternativas na perspectiva da educação indígena foi desenhado a partir do impacto, da importância e da decisão (persuasão e difusão de ideias) para uma análise qualitativa. A questão definida que auxiliou na composição desse fluxo no âmbito local foi: 5) Dentro das políticas afirmativas (a exemplo das cotas nas universidades), qual a importância e impacto da política pública indígena?

A importância do simbólico é absoluta, eu contaria muito mais com o simbólico do que com o material, o material você vai mais para o número, que é muito pequeno relativamente, mas o simbolismo de estarem dentro desses espaços é muito grande para todos, não só para a comunidade indígena como um todo, para a pessoa que

Revista Expectativa, Toledo/PR, v.20, n. 4, p. 133-154, out./dez., 2021. 
está fazendo, mas muito especialmente para a sociedade, que ela é toda restritiva, não é. (Entrevistado C).

A lei de cotas pode criar, inadvertidamente, uma dificuldade, porque quando se engloba diferentes destinatários da política em uma única regra, e principalmente, aquele que o percentual indígena da população pelo IBGE é mínimo, então o risco da dissolução completa da política, para os estudantes indígenas, no interior dessa política geral é imenso. (Entrevistado E).

O egresso faz a ponte entre universos, mundos que são diferentes sim, relação com o Estado com o poder público e relação com as suas coletividades. Não é fácil, e extremamente assimétrica, por questões de cosmologias diferenciadas, línguas. Alinhavar entendimento comum com os povos indígenas, o respeito que está na Constituição (1988). Os impactos são em todos os espaços. Precisamos avançar no ponto de vista dos cursos, de vagas. É preciso avançar nos processos. Já temos os primeiros indígenas mestres, doutores, professor concursado. (Entrevistado B).

Nessa questão da política local apareceram documentos relativos à política em âmbito nacional, como a Constituição Federal de 1988 e local como o Relatório do Plano de Metas de Inclusão Racial e Social na UFPR.

Podemos considerar a Constituição Federal de 1988 de acordo com algumas concepções, como um marco da discussão, aparecendo como policy windows, ou seja, "janela de oportunidades", embora esse seja um ponto de vista e reconhece-se que várias são as interpretações dadas à Carta Magna. Para alguns estudiosos e gestores, a eclosão das discussões e as ações desempenhadas partem da Constituição Federal de 1988 e até mesmo da Constituinte, em contraponto, para outros atores o ponto de partida pode ser considerado a Conferência de Durban e outros eventos ou leis, como a LDB.

Conforme consta na Constituição Federal de 1988, Art.231 assegura-se aos índios no Brasil permanecerem com suas línguas, culturas e tradições. Considerando principalmente no caso da implementação da política local o documento de diretrizes, a Resolução 37/04 foi implementada no ano de 2004, na UFPR, (partes destacadas da Resolução n. 37/04-COUN, alteradas e com nova redação: - Alterado pela Resolução n. 17/07-COUN, de 16 de maio de 2007, publicada em 29 de maio de 2007 - Nova redação dada pela Resolução n. 41/04-COUN, de $1^{\circ}$ de junho de 2004dispõe que: Considerando as diretrizes lançadas pela Constituição Federal para a formação de políticas e programas que interfiram positivamente na erradicação da pobreza e redução das desigualdades com vistas a construir uma sociedade justa e solidária.

Entretanto, e naturalmente, a agenda no âmbito nacional e no âmbito local se desenham de distintas formas. A Agenda de Kingdon (2011) estabeleceu uma importante fundamentação 
teórica para o conhecimento do processo de formulação política: "Ele definiu a agenda política como 'a lista e assuntos a que funcionários do governo e aqueles ao seu redor estão prestando séria atenção", , tradução nossa. ${ }^{3}$

A adoção do Modelo de Múltiplos Fluxos desenvolvido por Kingdon (2011) torna-se adequado à análise que se propõe, concentrada na fase de formação da agenda, trazendo, assim, os desdobramentos da política dispostos em leis, decretos, resoluções em âmbito nacional, e resoluções, planos e programas em âmbito local.

A agenda, no âmbito nacional, é composta pela Lei de Diretrizes e Bases, pelo Plano Nacional de Educação, pelas ações do Conselho Nacional de Educação entre outras. A agenda, no âmbito local, é composta pela Resolução 37/04, pelos Planos de Metas 2004 e pelos programas e ações.

Esse levantamento e análise foram realizados considerando a pesquisa em nível de pósgraduação stricto sensu, a atuação e experiência da profissional de Secretariado Executivo que trabalha na UFPR neste espoco, buscando maior abrangência da temática, visibilidade da atuação, relevância das questões postas e contribuição social e profissional.

\section{CONSIDERAÇÕES FINAIS}

O avanço nas políticas e leis é, entre outros aspectos, fruto da conquista de movimentos sociais e indígenas dentro do escopo dessa pesquisa e, portanto, se reconhece a importância da temática ser debatida e compreendida na sociedade, especialmente dentro das Universidades e do espaço governamental.

Esta pesquisa procurou analisar a ação dos gestores institucionais, dos movimentos sociais, da comunidade acadêmica. Também verificou a ocorrência de mudança das ações políticas principalmente na gestão 2002/2006 com a entrada mais efetiva da pauta na agenda política institucional da Inclusão Racial e Social na UFPR.

Isso se tornou possível através da atuação, experiência e pesquisa da profissional de Secretariado Executivo neste espaço para além da atuação de outros servidores, trabalhando nas

\footnotetext{
3 "He defines the policy agenda as 'the list of subjects to which government officials and those aroud them are paying serious attetion'”' (KINGDON, 2011, prefácio, vii, tradução nossa)

Revista Expectativa, Toledo/PR, v.20, n. 4, p. 133-154, out./dez., 2021.
} 
dimensões interpessoais, interculturais e utilizando da intelectualidade e sensibilidade para melhor atender e valorizar esses atores, essas conquistas e avanços.

Os elementos institucionais e históricos que levaram à adoção dessa política na UFPR vieram à tona através de três perspectivas, no que tange à revisão da literatura que apresentou o recurso histórico da política de forma geral, do levantamento documental conforme disposto na Resolução n. 37/04, no Relatório e Exposição de Motivos para o Plano de Metas da Inclusão Racial e Social na UFPR - 2004 e no Relatório da Comissão encarregada de avaliar os 10 anos de implantação do Plano de Metas de Inclusão Racial e Social na UFPR (2015). Entre outros, bem como a riqueza de detalhes que emergiram dos relatos constantes nas entrevistas dos gestores e informantes-chave (policy enterpreneurs/empreendedores de política) sob seu lócus de atuação e sua percepção da vivência no percurso histórico de implementação da política.

Há uma gama de atores que aparecem ao longo do estudo: a Gestão 2002-2006, todos os Conselheiros, sejam servidores docentes, servidores técnico-administrativos, sejam estudantes (presentes na discussão à época), a comunidade acadêmica, grandiosas e pontuais ações protagonizadas pelo Movimento Negro e Movimento Indígena, pelos Indigenistas, pela Sociedade Civil e organização dos Movimento Sociais, Organizações não Governamentais (ONGs), atores presentes nas Comissões de Implementação e de Avaliação do Plano, enfim, pessoas engajadas na luta por direitos e implementações dessa políticas públicas visadas para as ditas "minorias".

Assim, os objetivos da pesquisa foram atingidos, a política pública local se desdobrou em resoluções, planos, metas. A pertinência da pesquisa na temática indígena com a análise da referida metodologia de políticas públicas Modelo de Múltiplos Fluxos de Kingdon (2011) na perspectiva local se apresentou diferenciada e protagonista, e o papel de atuação e pesquisa do profissional de Secretariado Executivo nessa área e temática, foi fundamental, marcante e avançado.

Essa política pública afirmativa se torna imprescindível a partir do momento que reflete, propõe e de fato oportuniza o diálogo e as trocas culturais, sociais, territoriais (que impactam o desenvolvimento) com as alteridades indígenas nesse lócus da universidade.

Nesse sentido, fica a audácia de uma sugestão de resistência política para o enfrentamento das lutas pelas políticas afirmativas. Reconhece-se que, com esta opção, este trabalho poderá cumprir o papel de instigar a academia e todas as pessoas que se interessam em 
pensar sobre a significância, a importância do papel das políticas públicas, tendo como pano de fundo a educação indígena em que pese o âmbito nacional ou local e, ainda, educação em nível básico, médio ou superior. Partindo ainda para a análise de outras políticas afirmativas tão importantes quanto essa.

Ressalta-se que a pesquisa poderá ser utilizada pela academia com direta interface com o corpo técnico administrativo, com nível gerencial, com os indigenistas e indígenas interessados na discussão da política pública educacional superior indígena. A pertinência da pesquisa na temática indígena, com a análise da referida metodologia de políticas públicas - o Modelo de Múltiplos Fluxos, de Kingdon (2011) - na perspectiva local apresenta-se diferenciada e protagonista.

O fato dos estudantes indígenas estarem na universidade faz com que as instituições (ainda que paulatinamente e com vários desafios) revejam suas estruturas, e encaminhem ações e programas afirmativos para o atendimento desses.

A atuação do profissional de Secretariado Executivo presente nessa área e dentro dessa temática é essencial, não só por sua habilidade de lidar com as questões burocráticas, técnicas, organizacionais, mas ainda por seu desprendimento e compreensão de atuação intercultural, valorizando e respeitando essas alteridades, sendo um elo fortalecedor e potencializante da política.

\section{REFERÊNCIAS}

BARDIN, L. Análise de conteúdo. São Paulo: Edições 70, 2011.

BRASIL. Constituição (1988). Constituição da República Federativa do Brasil. Brasília, DF: Senado Federal, 1988.

BRASIL. Presidência da República. Decreto n. 7.824. Regulamenta a Lei n. 12.711, dispõe sobre o ingresso nas universidades federais e nas instituições federais de ensino técnico de nível médio. Brasília, 11 out. 2012.

BRASIL. Presidência da República. Lei n. 12.711/12. Dispõe sobre o ingresso nas universidades federais e nas instituições federais de ensino técnico de nível médio e dá outras providências. Diário Oficial da União, 30/08/2012. Brasília, 29 ago. 2012.

BRASIL. Presidência da República. Lei n. 6.556/78. Dispõe sobre a atividade de Secretário e dá outras providências. Brasília, 5 set. 1978. 
BRASIL. Presidência da República. Lei n. 7.377. Dispõe sobre o Exercício da Profissão de Secretário, e dá outras Providências. Brasília, 30 set. 1985.

BRASIL. Presidência da República. Lei n. 9.394. Estabelece as diretrizes e bases da educação nacional. Lei de Diretrizes e Bases da Educação Nacional - LDB. Brasília, 20 dez. 1996.

BRASIL. Presidência da República. Lei n. 9.261. Altera a redação dos incisos I e II do art. $2^{\circ}$, o caput do art. $3^{\circ}$, o inciso VI do art. $4^{\circ}$ e o parágrafo único do art. $6^{\circ}$ da Lei n. 7.377 , de 30 de setembro de 1985. Brasília, 10 de jan. 1996.

BRASIL. Supremo Tribunal Federal. Arguição de Descumprimento de Preceito Fundamental - ADPF 186. Brasília, 29 abril 2012.

BRITO, M. Secretariado intercultural: como auxiliar empresas e profissionais em negócios no exterior. São Paulo: Lura Editorial, 2015.

BRITO, M.; SAMPAIO, J. Para um Novo Paradigma no Secretariado: a assessoria humanizada. COMSECDF. E-book, 2018. Disponível em:

https://docs.wixstatic.com/ugd/f09f28_8028cd9f18e64cdcb8aec239fbceb67e.pdf. Acesso em: 22 fev. 2019.

FEDERAÇÃO NACIONAL DAS SECRETÁRIAS E SECRETÁRIOS. A FENASSEC. 2014. Disponível em: http://www.fenassec.com.br/site/. Acesso em: 29 mar. 2019.

FONSECA, D. J. Políticas Públicas e ações afirmativas. Coleção Consciência em Debate. São Paulo: Selo Negro, 2009.

FUNDAÇÃO NACIONAL DO ÍNDIO. Quem somos, 1967. Disponível em: http://www.funai.gov.br. Acesso em: 26 fev. 2016.

GIORNI, S. Secretariado, uma profissão. Belo Horizonte: Editora Quantum Projetos Ltda ME, 2017.

GOMES, J. B. B. Ação Afirmativa \& Princípio Constitucional da Igualdade: o direito como instrumento de transformação social. A experiência dos EUA. Rio de Janeiro: Renovar, 2001.

GRUPIONI, L. D. B. As leis e a educação escolar indígena: Programa Parâmetros em Ação de Educação Escolar Indígena. Brasília: Ministério da Educação, Secretaria de Educação Fundamental, 2002.

GUARNIERI, F. V.; MELO-SILVA, L. L. Ações afirmativas na educação superior: rumos da discussão nos últimos cinco anos. Psicologia \& Sociedade. v. 19, n. 2, maio - ago., 2007. 
KINGDON, J. W. Agendas, alternatives, and public policies. United States: Longman, 2011.

LARAIA, R. B. Cultura, um conceito antropológico. Rio de Janeiro: Jorge Zahar, 2000.

LIMA, M. Desigualdades raciais e políticas públicas: ações afirmativas no governo Lula. Novos Estudos Cebrap, n. 87, p. 77-95, 2010.

MEDEIROS, J. B.; HERNANDES, S. Manual da Secretária. 12. ed. São Paulo: Atlas, 2010.

MOEHLECKE, S. Propostas de ações afirmativas no Brasil: o acesso da população negra ao ensino superior. Dissertação de mestrado. Universidade de São Paulo, São Paulo, SP, Brasil, 2000.

MUNANGA, K. Considerações sobre as Políticas de Ação Afirmativas no Ensino Superior. In: PACHECO, J. Q.; SILVA, M.N. (Orgs.). O negro na universidade: o direito à inclusão Brasília: Fundação Cultural Palmares, 2007.

NONATO JÚNIOR, R. N. Epistemologia e Teoria do Conhecimento em Secretariado Executivo: a fundação das ciências da assessoria. Fortaleza: Expressão Gráfica, 2009.

OLIVEIRA, V. S. Entre desafios e oportunidades: análise da política afirmativa educacional superior indígena na UFPR. 2016. Dissertação (mestrado em Desenvolvimento Territorial Sustentável) - Universidade Federal do Paraná, Matinhos/PR, 2016.

OLIVEIRA, V. E. de. As fases do processo de políticas públicas. In: MARCHETTI, V. (Org.). Políticas públicas em debate. São Bernardo do Campo: ABCD Maior/UFABC, 2013.

SABINO, R. F.; ROCHA, F. G. Secretariado: do escriba ao web writer. Rio de Janeiro: Brasport, 2004.

SABINO, R. F.; MARCHELLI, P. S. O debate teórico-metodológico no campo do secretariado: pluralismos e singularidades. Cadernos Ebape. BR, v. 7, n. 4, Rio de Janeiro, 2009.

SANTIAGO, C.; FRANÇA, E. Secretariado \& Sustentabilidade. João Pessoa: UFPB, 2018.

SECCHI, L. Políticas Públicas: conceitos, esquemas de análise, casos práticos. 2. Ed. São Paulo: Cengage Learning, 2014.

SECRETARIA DE POLÍTICAS DE PROMOÇÃO DA IGUALDADE RACIAL. SEPPIR. 2015. Disponível em: http://www.seppir.gov.br. Acesso em: 20 mar. 2015.

SILVA, C. L. da. (Org). Políticas públicas e desenvolvimento local: instrumentos e proposições de análise para o Brasil. Petrópolis: Vozes, 2012. 
SOUZA, C. Estado da arte da pesquisa em políticas públicas. In: HOCHMAN, G.; ARRETCHE, M.; MARQUES, E. (Orgs.). Políticas Públicas no Brasil. Rio de Janeiro: Fiocruz, 2012

SOUZA, E. C. P.; VIANA I.; SILVA, S. Estudos de gênero e diversidade no contexto do secretariado: antigos dilemas, novos olhares. São Paulo: SINSESP, 2017.

UNIVERSIDADE FEDERAL DO PARANÁ. Relatório e exposição de motivos para o Plano de Metas da Inclusão Racial e Social na Universidade Federal do Paraná. Curitiba, 2004.

UNIVERSIDADE FEDERAL DO PARANÁ. Pró-Reitoria de Graduação e Ensino Profissionalizante. Relatório do Plano de Metas da Inclusão Racial e Social na Universidade Federal do Paraná. Curitiba, 2015.

UNIVERSIDADE FEDERAL DO PARANÁ. Resolução n. 37/04 - COUN. Curitiba, 2004. UNIVERSIDADE FEDERAL DO PARANÁ. Termo de Convênio 502/2004. Curitiba, 2004. UNIVERSIDADE FEDERAL DO PARANÁ. Termo de Cooperação 02/2006. Curitiba, 2006.

YIN, R. K. Estudo de caso: planejamento e métodos. Tradução D. Grassi. 2. ed. Porto Alegre: Bookman, 2001. 